\title{
A questão da intersubjetividade em Michel Foucault
}

\section{Francisco Guerrero Ortesa/VFG}

\section{Resumo}

Neste artigo, o autor apresenta a dimensão intersubjetiva da autoconstituição ética do sujeito.
Abstract

In this article, the author presents the intersubsjective dimension of the ethical selfconstitution of the subject.

Ocuidado de si (...) aparece como uma intensificação das relaçōes sociais. (Foucault, 1984b, p. 74).

Analogamente ao caso de Heidegger, Foucault é acusado de não haver tematizado esta dimensão. ${ }^{1} \mathrm{~A}$ autoconstituição foucaultiana do sujeito exigiria uma subjetividade "monádica" (McNay, 1992, p. 180), capaz de acolher $o$ outro unicamente na forma de "subjetividade ampliada" (erweiterte Subjetivität) (Heiter 1988, p. 67). A pergunta que se nos apresenta é a seguinte: evitou Foucault por princípio a dimensão intersubjetiva nas suas análises da autoconstituição antiga - como uma parte da crítica afirma - ou não se poderia afirmar antes que ele pensou-a não nas categorias correntes de uma fenomenologia da intersubjetividade baseada na experiência da empatia (Einfühlung) ou de uma teoria da comunicação?

Parece-me pouco plausível afirmar que Foucault prefere um si mesmo isolado nas suas investigações sobre a ética grega e romana, pois a relação com o outro constituía uma constante em toda a tematização do si mesmo na Antiguidade e na sua incorporação às técnicas da pastoral cristã. Nesse sentido Wilhelm Schmid (1991, p. 245) fala de uma "filosofia da relação" que substitui a filosofia do sujeito, visto que a relação consigo mesmo aparecia em toda a história do cuidado de si, inseparável da relação com o outro. Eu, por minha parte, falarei de uma concepção agonística da intersubjetividade nas análises foucaultianas da cultura do si mesmo. A noçāo extrovertida de subjetividade, a consciência orientada para fora, o caráter reflexivo do si mesmo descrito pelo movimento do "desprender-se de si mesmo", 2 corresponde a essa experiência agonística da intersubjetividade. Tal encontro do outro produz "uma prova transformadora de si mes- 
mo" em vez de "uma apropriação simplificadora do outro com o fim da comunicação" (Foucault, 1984a, p. 16).

Em primeiro lugar apresentarei a dimensão intersubjetiva nas investigaçōes de Foucault sobre a ética antiga. Esta não é somente tratada nos volumes II e III da História da sexualidade, mas também nos cursos sobre $A$ hermenêutica do sujeito, particularmente na análise do Alcebíades platônico - e sobre a parrhesia, nas quais ocupa o lugar central a relaçāo com o outro.

Num primeiro passo será mostrado como o cuidado dos outros, sob a forma da intersubjetividade agonística, de um "desligamento duplo" (Deleuze), acompanha toda a experiência da autoconstituição platônica. ${ }^{3} \mathrm{Um}$ segundo passo tem como objeto a "autofinalização do cuidado de si" (Foucault, 1985b, p. 44ss.), a qual tem lugar os séculos I e II de nossa era e está caracterizada pela dissociação do cuidado de si do cuidado dos outros. Esta não tem como resultado o descuido do outro, mas antes a intensificação das relações sociais (as quais incluirão os elementos de reciprocidade e de simetria), além da formação de uma práxis social. As cartas de Sêneca a Lucilius constituem um exemplo excepcional nesse sentido.

A pastoral cristã mantém o vínculo intersubjetivo - na Antiguidade tinha a forma da amizade e a relação mestre-aluno - que vai ser exprimido, porém, numa relação de obediência. Com isso, o cuidado de si perde autonomia e é integrado no âmbito da pastoral. A relação entre dois sujeitos, na qual cada um participava, mediante o cuidado de si, do cuidado do outro, transforma-se em uma relação onde o pastor, como diretor das almas, tem como tarefa a administração do cuidado. A epimeleia heautou vira epimeleia ton allon (Foucault, 1987, p. 290).

Um terceiro e um quarto passos analisam a concepção da intersubjetividade em Heidegger e Lévinas. A escolha desses autores permite obter uma série de ganhos teóricos que podem servir como complemento da intersubjetividade agonística foucaultiana. A análise de Heidegger do sercom (Mitsein) como a dimensão intersubjetiva do Dasein possibilita uma experiência do outro, que não possui a forma da empatia (Einfühlung) husserliana. O outro encontra-se "no trabalho" (bei der Arbeit), ou seja, na forma do "ser-no-mundo" (In-der-Welt-seins): ele vai ser apreendido como outro Dasein (Heidegger, 1986, p. 118, 110, 123). Como conseqüência, a empatia (Einfühlung) experimenta uma viragem copernicana, visto que ela não constitui o Mitsein (ser-com), mas é seu resultado (idem, 125).

A fenomenologia do outro de Emmanuel Lévinas orienta-se também contra a fenomenologia da intersubjetividade de Husserl e advoga por uma 
experiência da subjetividade que tenha a intersubjetividade como sua condição de possibilidade: somente mediante o outro é a experiência do si mesmo possível. De maneira análoga a Foucault e Heidegger, não se trata de uma experiência do outro subsumível no si mesmo, mas antes de uma experiência de sua alteridade, da "crença no ethos do autor", utilizando uma expressão de Peter Szondi.

\section{Cuidado de si e cuidado dos ou- tros na ética socrático-platônica}

Já no curso de 1980-1981 no Collège de France com o tema Subjetividade $e$ verdade, Foucault concebe a história do cuidado de si como ponto de interseção da história da subjetividade e da análise das diferentes tecnologias de governo (Foucault, 1989, p. 134). A consideração da problemática do governo sob a perspectiva de uma história do cuidado de si permite introduzir a temática da intersubjetividade, pois o objetivo vai ser a análise "do governo de si mesmo em sua relaçāo com as relaçōes com o outro (como as encontramos na pedagogia, nas regras de comportamento, na direção da alma, no decreto de formas de vida etc.)". "Trata-se para Foucault de uma experiência que une "a relação consigo mesmo e a relação com os outros". Assim, ele anuncia em 1982 seu interesse da seguinte maneira: "Como se chega por meio do cuidado à técnica (technè) do governo dos outros?" (1985a, p. 36).

A questão da relação com o outro é uma constante em toda a temática do cuidado de si. Foucault sublinha em numerosas ocasiōes a necessidade desse vínculo intersubjetivo (em forma agonística). Sem a presença de um outro, não se pode produzir nenhum auto-relacionamento satisfatório: "não se pode ocupar-se de si mesmo, cuidar-se de si mesmo, sem ter uma relação com um outro" (1988, p. 17).

A constituição do indivíduo como sujeito ético se efetua só por meio de relações complexas com o outro (cujos status e formas são diferentes segundo a época). O outro é indispensável na cultura do si mesmo. ${ }^{5}$

O diálogo platônico Alcebíades constitui um exemplo especial para mostrar a esfera intersubjetiva do cuidado de si. Jermann (1986, p. 67ss.) localiza a dimensão intersubjetiva precisamente na escolha do diálogo como forma de filosofar: "O diálogo filosófico mesmo é o que é importante para Sócrates (...). A filosofia não era para o mestre de Platão um fim em si mesmo, senão o filosofar coletivo, a intersubjetividade filosófica." 6

O diálogo (Alcebiades) pode-se dividir em três partes: ${ }^{7}$ uma primeira que acentua a necessidade da relação Sócrates-Alcebíades, pois somente com a ajuda de Sócrates pode Alcebía- 
des levar a cabo seus assuntos (Platão, 1969: 106ass.). Na segunda parte, a partir do déficit de saber de Alcebíades, sublinha-se a importância do cuidado de si. Sua consistência pode ser deduzida somente mediante o conhecimento de si (118bss.). A última parte constitui uma tentativa de relacionar as duas primeiras partes: a necessidade da esfera intersubjetiva (exprimida na relação Sócrates-Alcebíades) vai ser ligada à relação entre cuidado de si e conhecimento de si (124bss.). À pergunta de Alcebíades: “Em que consiste, pois, esta formação cuidadosa?" (124c), Sócrates responde: “O conselho, mediante o qual seremos tão hábeis como for possível, deve ser em comum. (...) antes devemos considerar o assunto incansavelmente em conjunto."

A conversa como contexto intersubjetivo constitui a condição necessária de toda forma de auto-relacionamento e autotematização:

Este princípio da intersubjetividade é condição necessária, ou seja, o meio no qual é possível o "cuidado de si", isto é, a produção de uma relação consigo mesmo prática, permitindo assim ao indivíduo estabelecer uma auto-relação positiva segundo critérios intersubjetivos sobre o sucesso de suas práticas do si (Heiter, 1988, p. 60).

A questão da intersubjetividade pode ser formulada em dois niveis na ética socrático-platônica. Por um lado, a intersubjetividade, na forma do filosofar dialógico, constitui o contexto transcendental no qual pode surgir um esboço de si mesmo compreensível, isto é, a subjetividade na sua função significante. Somente num contexto intersubjetivo vai ser possível estabelecer uma relação consigo mesmo. A auto-estilização precisa de uma publicidade, embora esta consista somente em um indivíduo, no qual ela obtém seu sentido. Particularmente na lembrança e no reconhecimento revela-se a esfera intersubjetiva como necessária na constituição do cuidado de si. $^{8}$ Por outro lado, a intersubjetividade aparece como resultado do cuidado de si, na forma do cuidado dos outros. Esta última corresponde ao conceito introduzido por mim de uma intersubjetividade agonística. Trata-se da inseparabilidade da ética e da política ou da filosofia e da política na filosofia socrático-platônica: "(...) A exigência de cuidar-se de si mesmo e de cuidarse do estado são já para Sócrates basicamente inseparáveis." 9 Sobre esta relação estreita entre filosofia e política vai ser construída toda a concepção da intersubjetividade agonística nas análises foucaultianas da ética grega clássica: "O cuidado de si (aparece) como uma condição pedagógica, ética e também ontológica para a constituição do bom governador. Constituir-se como sujeito que governa implica se 
haver constituído como sujeito que cuida de si mesmo."10

Sobre o primeiro nível: $O$ indivíduo se constitui como sujeito moral na sociedade grega clássica, mediante uma atitude e uma busca "que pode modular e individualizar sua ação e até dar-lhe um esplendor singular, dotando-a de uma estrutura racional e reflexiva" (Foucault, 1984a, p. 82-3). A singularidade deste si mesmo, que deve ser criado segundo critérios estéticos, a fim de que possua glória e permaneça longo tempo na lembrança (reconhecimento e lembrança), vai ser somente compreendida em uma dimensão intersubjetiva. Com palavras de Bern Heiter:

Unicamente na relação com um outro livre é possível para o sujeito se diferenciar a si mesmo e sua estilizaçăo da do outro, mostrar seu valor como fundamentado e poder-se reconhecer reciprocamente na sua alteridade, pois a lembrança lograda e a própria reputação não são concebíveis sem o meio da intersubjetividade. "I

Sobre o segundo nivel: A intersubjetividade agonística contida no cuidado de si grego exprime-se mediante atividade, simetria e irreciprocidade, determinantes da relação com o outro. A produção de uma relação consigo mesmo, que tem a forma da virilidade ética, determina a forma da relação com o outro, como Foucault expōe nos capítulos sobre dietética, economia e erótica do Uso dos prazeres. Uma relação de hierarquia, domínio e autoridade define a forma dessa intersubjetividade agonística (Foucault, 1984a, p. 106-7, 110, 123, 196-7, 204, 221).

Foucault introduz a problemática da intersubjetividade como um desenvolvimento do pensamento governamental. Daí surge uma dupla relação com o outro:

$A$. A relação com o outro aparece como uma dobra da relação consigo mesmo: cuidado de si como condição do cuidado dos outros (a qual Foucault investiga principalmente em relação com o Alcebiades: um cuidava de si mesmo para poder cuidar dos outros), como um movimento do si mesmo para o outro. Nesse caso aparece a relação com o outro num segundo lugar, depois do estabelecimento da relação consigo mesmo (embora esta seja também orientada intersubjetivamente para o cuidado dos outros):

(...) não se pode dizer que o grego que se cuida de si mesmo, deve cuidar primeiro dos outros. (...) Não se deve colocar o cuidado dos outros diante do cuidado de si; sob uma perspectiva ética, aparece o cuidado de si em primeiro lugar na medida em que a relação consigo mesmo está ontologicamente em primeiro lugar. (Foucault, 1985a, p. 15)

A intersubjetividade agonística adota principalmente três formas que Foucault define como "vínculos" entre 
o si mesmo e o outro: 1.vínculo da finalidade: um se ocupa de si mesmo para poder ocupar-se dos outros; 2. vínculo da reciprocidade: cuidando de si mesmo, faz-se algo bom para a polis e, visto que um é também membro da polis, vai aproveitar o bem-estar de cada um; 3. vínculo da implicação essencial: cuidando de si mesmo, a alma descobre (na forma da lembrança) o que é e o que sabe (Foucault, 1985b, p. 43-4). Nos primeiros séculos de nossa era vai se desligar o cuidado de si do cuidado dos outros mediante a chamada autofinalização do cuidad o de si.

$B$. Ao mesmo tempo, o indivíduo que deseja cuidar de si mesmo precisa da presença de um outro, que lhe ajude na autoconstituição. Esse outro é na Grécia clássica normalmente o mestre. $O$ indivíduo "deve se constituir como sujeito e nesse ponto deve intervir o outro (...). Agora, o mestre é um operador na reconfiguração e formação do indivíduo como sujeito. Ele é o intermediário na relação do indivíduo com sua autoconstituição" (idem, p. 41). O mestre atua sobre o indivíduo, que quer produzir uma relação ética consigo mesmo, de três maneiras fundamentais denominadas por Foucault "mestrias":

1. Mestria do exemplo: em que exemplos tradicionais vão ser seguidos. ${ }^{12}$ 2. Mestria da competência: o mestre na sua posição de sábio trans- mite seu saber ao indivíduo que trabalha no cuidado de si. 3. Mestria das adversidades: corresponde à mestria socrática do se expor a si mesmo (idem, p. 40). O mestre é o único capacitado para tirar o indivíduo do estado de "estupidez" (stultitia), entendido como um estado de não querer se salvar, e ajudá-lo na produção de uma relação consigo mesmo satisfatória.

Especialmente o Banquete oferece um exemplo ilustrativo do papel do mestre na autoconstituição: mediante seu poder como mestre da verdade, encarnado por Sócrates, será possível para o rapaz ascender de seu status de objeto a um status de sujeito (Foucault, 1984a, p. 289-306).

O mestre se ocupa do cuidado de si mesmo que o sujeito tem e encontra no amor por seu aluno a possibilidade de se ocupar do cuidado de si que o aluno mesmo tem. Amando o rapaz de uma forma desinteressada, ele é o princípio e modelo do cuidado de si que o rapaz deve ter como sujeito. ${ }^{13}$

Nos primeiros séculos de nossa era a função do mestre foi desempenhada por um grupo de indivíduos. $O$ mestre como intermediário da autoconstituição prova o pouco sentido que tem falar em Foucault a partir de uma concepção monádica da subjetividade, do aprisionamento na filosofia do sujeito (Lois McNay) ou da intersubjetividade como uma mera ampliação da subjetividade (Bern Heiter). 
Então, a relação com o outro apresenta-se como indispensável para o estabelecimento da relação consigo mesmo. Não existem auto-estilizaçōes em solidão. Toda auto-apresentaçāo (até nas formas privadas da autobiografia ou do diário) está orientada intersubjetivamente. A noção de um si mesmo, o qual precisa de um outro para constituir sua própria subjetividade, assemelha-se à concepção de subjetividade de Emmanuel Lévinas, como vai ser mostrado.

\section{Intersubjetividade e autofinaliza- ção do cuidado de si}

Nos séculos I e II de nossa era chega-se à "autofinalização do cuidado de si", à idade de ouro da cultura do si mesmo (Foucault, 1984b, p. 5594; 1985b, p. 44ss.; 1987, p. 280; 1989, p. 149ss.). O domínio de si característico da ética grega clássica desliga-se do domínio dos outros; o cuidado de si não é mais a pressuposição do cuidado dos outros. $O$ primeiro converte-se num fim em si mesmo, aparece "ensimesmado" em si mesmo. Um duplo processo vai ter lugar: "Uma absolutização do si mesmo como objeto do cuidado e uma autofinalização do si mesmo mediante a prática chamada 'cuidado de si'" (1985b, p. 45). A intersubjetividade agonistica experimenta uma transformação, pois a constituição de si mesmo como sujeito ético torna- se mais problemática: já não aparece na relação de isomorfismo, mediante a qual era definida na Grécia clássica (1984b, p. 114s.). Ela (a intersubjetividade agonística) vai ter que acolher o elemento da reciprocidade: "Dono de si mesmo não se deve ser unicamente para dominar os outros mas por ser um ser racional. Neste domínio de si o individuo está unido a outros indivíduos que são igualmente donos de si mesmos. Este tipo de relação com o outro é muito menos recíproca que antes" (1987, p. 280).

Essas transformaçōes, essa intensificação da relação consigo mesmo não tem como conseqüência o aumento do individualismo mas antes (o que poderia parecer paradoxal) um reforço das relaçōes sociais: "a intensificação do cuidado de si implica a revalorização do outro" (1984b, p. 195). Apesar da dissociação do cuidado dos outros, a relação com o outro continua sendo indispensável para o cuidado de si.

O papel do mestre como o outro singular e intermediário na autoconstituição da tradição socrático-platônica vai ser superado, pois a prática do si mesmo transcende seu contexto originário da práxis filosófica. Essa função não vai ser somente relizada pelo mestre, pelo filósofo, mas por uma série de indivíduos. ${ }^{14}$ Em redor da práxis do si mesmo vão surgir uma série de estruturas (mais ou menos) institucionalizadas, por exemplo, a escola de Epícteto, 
as comunidades neopitagóricas ou a figura do conselheiro privado que, pelo menos em Roma, desempenha funções múltiplas (Foucault, 984b, p. 71ss.; 1989, 153ss.). A dimensão intersubjetiva da cultura do si mesmo desenvolve-se, porém, não somente num contexto institucionalizado, mas também nas relaçóes correntes de parentesco, compromisso ou amizade. Relaçóes que implicam uma forte ligação intersubjetiva e nas quais o papel do outro na constituição de uma relação recíproca consigo mesmo é essencial. A correspondência de Sêneca constitui um exemplo fundamental deste processo.

Interessante nessa correspondência é o já mencionado elemento da reciprocidade na relação intersubjetiva. Tanto Sêneca quanto Lucilius trabalham mediante essa relação epistolar em sua autoconstituição. Sêneca comporta-se nas cartas tanto como mestre quanto como aluno (Schottelaender, 1975, p. 174; Misch, 1950, p. 428). Ante Lucilius apresenta-se como "diretor da alma", ao mesmo tempo oferecelhe essa relação uma possibilidade de trabalhar sobre si mesmo: "Sua obra de formação lhe obriga a seguir no seu auto-aperfeiçoamento; como seu pupilo, ele deve se esforçar com maior razão em se superar dia a dia." (Knoche 1975, p. 163; Cf. Veyne, 1993, 589; Sorensen, 1984, p. 194).
A escolha da correspondência como forma da relação intersubjetiva obedece a uma noção comum desde a Antiguidade segundo a qual a carta tem a maior proximidade com a conversa (diálogo). A formação (recíproca) efetiva acontece unicamente pela reuniāo (contubernium). Por conseguinte, a comunicação curta mas diária em forma epistolar oferece a continuatio necessária. Essa forma do ser-como-outro vai ser praticada na tradição monástica no lugar da conversa, para a qual não existe espaço (Misch, 1950, I/2 586; II/2 443).

As cartas a Lucilius contêm, além disso, um componente importante de auto-apresentação, que, porém, não exclui a função do outro na autoconstituição. ${ }^{15}$

O papel do outro é indispensável para a produção de um esboço de si mesmo compreensível. Esse pensamento constitui uma constante de toda a tradição greco-romana. Portanto, Foucault não reivindica nas suas análises uma autoconstituição isolada que exclua qualquer relacionamento com o outro, senão para ele está sempre presente o outro na origem da constituição estética de si mesmo, na figura do mestre, guia, professor, diretor de consciência ou amigo. A tradição cristã incorpora essa relação com o outro na forma de um vínculo de obediência. Esta conduzirá, junto com o exame de consciência e a confissão à constituição 
de uma relação consigo mesmo cujo objetivo é a renúncia de si mesmo, a auto-anulação. A intersubjetividade, como a tarefa de trabalhar em conjunto no cuidado de si e do outro, distingue-se claramente das relações com o outro cristās e modernas orientadas ao poder pastoral e ao biopoder; relações des-cuidantes.

\section{Cuidado (Sorge) e ser-com (Mitsein) em Heidegger}

O quarto parágrafo do primeiro capítulo da primeira parte de $\operatorname{Ser} e$ tempo (Sein und Zeit), "O ser-nomundo como ser-com e ser-si- mesmo" (Das In-der-Welt-sein als Mit- und Selbstsein) analisa a estrutura intersubjetiva do Dasein. A estrutura ontológica do ser-no-mundo (In-der-Weltsein) exclui a possibilidade de encontrar um sujeito isolado (Heidegger, 1986, p. 116). O objetivo vai ser para Heidegger interpretar ontologicamente esse modus do ser-com (Mitsein) outros.

Primeiramente, Heidegger distingue o encontro do outro do encontro de entes intramundanos (innerweltliche Seinden) sem caráter de Dasein. Esses últimos vêm ao encontro na forma da ocupação (Besorgen) como um estar à mão (Zuhandenen) (idem, p. 72-6). Tal forma de encontro diferencia-se do encontro do outro, 0 qual tem um caráter de Dasein (welcher einen daseinsmässigen Charakter hat): "O mundo do Dasein libera, portanto, entes que não apenas se distinguem dos instrumentos (Zeug) e das coisas mas que, de acordo com seu modo de ser (Seinsart) de Dasein, são e estão 'no' mundo em que vêm ao encontro segundo o modo de ser-nomundo" (idem, p. 118). Esse ente que é o outro está também aí (ist auch mit $d a)$. Heidegger acentua precisamente esse "estar também aí" (mit auch da sein) para diferenciá-lo, por um lado, do modus do ser simplesmente dado em conjunto (Mit-Vorhandensein) e, por outro lado, para sublinhar seu caráter de Dase in, isto é, de um sendono-mundo (In-der-Welt-Seindens): “O mundo do Dasein é mundo compartilhad o (Mitwelt). O ser-em (In-Sein) é ser-com (Mitsein) outros. O ser-em-si intramundano (innerweltliche Ansichsein) destes é co-Dasein (Mitdasein)" (idem, p. 118). Nisso Heidegger se distancia de uma experiência da intersubjetividade orientada a Husserl. Posto que o Dasein não se encontra a si mesmo como um cogito isolado, mas "no que está imediatamente à mão (Zuhandenen) no mundo circundante, em sua ocupaçāo" (idem, p. 119), ou seja, "no que faz, precisa, espera, preserva", o Dasein encontra o outro "no trabalho" (bei der Arbeit), no seu "serno-mundo" (idem, p. 120): “Nas ocu- 
pações com o mundo circundante, os outros nos vêm ao encontro naquilo que são. Eles são o que empreendem" (idem, p. 126).

Em contraposição a Husserl não nasce a intersubjetividade para $\mathrm{Hei}-$ degger mediante a empatia (Einfühlung) ${ }_{1}^{16}$ senão, ao contrário, a empatia (Einfühlung)vai ser possível mediante a experiência do ser-com (idem, p. 125). O fato de compartilharmos práticas (culturais, de comunicação, do si mesmo) com outros constitui o contexto intersubjetivo como a base comum que possibilita o encontro do outro (Dreyfus/Rabinow, 1990, p. 62; Dreyfus, 1992, p. 149).

Importante é que para Heidegger o ser-com (Mitsein) deve ser apreendido como uma estrutura ontológica, como um existencial (existenzial). Até quando não há nenhum outro presente, esse estar-sozinho (Alleinsein) constitui um modus (deficiente) do ser-com. O Dasein é primeiramente ser-com, isto é, aberto para os outros: "Dentro do mundo, esse co-Dasein dos outros só se abre para um Dasein e assim também para os que estão aí (Mitdaseienden), visto que o Dasein é em si mesmo, essencialmente, sercom" (idem, p. 120). Heidegger se preserva de deduzir a constituição do Dasein a partir do encontro com o outro, a partir do ser-com (como Lévinas faz), afirma antes que o Dasein tem a possibilidade (devido a sua estrutura existencial-ontológica como ser-com) de encontrar outros entes com caráter de Dasein (daseinsmässigen Seienden) em seu modus de Dasein, isto é, como sendo-no-mundo e não como seres simplesmente dados (Vorhandenen) ou à mão (Zuhandenen):

Ser-com é sempre uma determinação do próprio Dasein; co-Dasein caracteriza o Dase in de outros na medida em que, pelo mundo do Dase in, libera-se a possibilidade para um ser-com. O próprio Dasein só é na medida em que possui a estrutura essencial do ser-com, enquanto co-Dasein que vem ao encontro dos outros. $^{17}$

A forma de encontro do outro que Heidegger distingue da ocupação (Besorgen) como encontro dos instrumentos à mão (zuhandenen Zeugs) vai ser denominada preocupação (Fürsorge): “O ente, com o qual o Dasein se comporta enquanto ser-com, também não possui o modo de ser do instrumento à mão, pois ele mesmo é Dasein. Desse ente não se ocupa, com ele se preocupa" (idem, p. 121). O ser-com-ooutro (Miteinandersein) expresso na preocupação desdobra-se em modi diferentes: em primeiro lugar modi da deficiência e da indiferença, caraterísticos da convivência cotidiana e mediana de um com outro, antes de se dedicar aos modi positivos conduzidos mediante consideração (Rücksicht) e 
tolerância (Nachsicht). Segundo o primeiro modus positivo da preocupação (substituinte-dominante) (einspringend-beherrschend) o outro vai ser dispensado de seu cuidado (Sorge): "Essa preocupação assume a ocupação que outro deve realizar. Este é deslocado de sua posição, retraindose, para posteriormente assumir a ocupação como algo disponível e já pronto (fertig Verfügbares)" (idem, p. 122). Essa relação intersubjetiva pode conduzir a um vínculo de dependência e domínio. Frente a este, o segundo modus da preocupação (anteposição liberadora) (vorspringend-befreiend) não dispensa o outro de seu cuidado, senão que este vai lhe ser devolvido. Essa relação com o outro "ajuda ao outro a ser diáfano e $m$ seu cuidado e livre para ele" (idem.).

A análise heideggeriana da antecipação da morte (Vorlaufen zum Tode) oferece uma tematizaçāo ulterior da intersubjetividade em Ser e tempo. No ser-para-a-morte (Sein zum Tode), a morte se mostra como a possibilidade mais própria (eigenste) do Dase in, como seu próprio ser si mesmo (eigentliches Selbstsein). Essa possibilidade não é só a mais própria mas é também irremissivel (unbezüglich). Isso significa que em presença da morte o Dase in vai ser devolvido a seu ser singular (Einzelsein): "A morte não apenas 'pertence' de forma não indiferente ao próprio Dasein, como reivin- dica o Dase in enquanto singularidade. A irremissibilidade da morte, compreendida na antecipação, singulariza o Dasein em si mesmo" (idem, p. 263).

O ser-com como modus do Dasein "falha" para Heidegger quando se trata de seu poder-ser mais próprio. Essa falha não significa a renúncia à dimensão intersubjetiva do Dasein exprimida no ser-com. $O$ sercom permanece como um modus do Dasein. A antecipação da morte como a possibilidade mais autêntica e irremissível do Dasein "não significa, contudo, de forma alguma, que esses modos do Dasein se descartem de seu ser próprio em sua propriedade" (idem, p. 263), pois "enquanto estruturas essenciais da constituição do Dasein, esses modos também pertencem à condição de possibilidade da existência" (idem). Precisamente, a morte oferece ao Dase in a oportunidade de "se fazer compreensivel como ser-com para o poder-ser (Seinkönnen) do outro" (idem, p. 264).

No parágrafo 34 de Ser e tempo, "Da-Sein e fala. A linguagem" (DaSein und Rede. Die Sprache), vai ser acentuada a dimensão intersubjetiva da linguagem na forma da fala (Rede). Precisamente essa linguagem apreendida como fala pressupóe um ouvir (Hören) como compreender (Verstehen) ("O Dase in ouve porque compreende"): "O ouvir é constitutivo da fala" (idem, p. 163). O ouvir constitui 
a abertura própria do Dasein: "como um ouvir da voz do amigo que todo Dasein leva consigo" (idem). Na fala apreende-se e constitui-se a intersubjetividade ("O ser-com é 'expressamente' dividido na fala", idem, p. 162), pois no ouvir-um-ao-outro ( $A u$ feinander-Hören) constitui-se o sercom. Importante para Heidegger não vai ser o componente lingüístico da intersubjetividade mas os modi diferentes possíveis mostrados pelo ser-com constituído nesse ouvir-um-ao-outro. Modi que, analogamente aos $m$ od $i$ do ser-com-o-outro expressos na preocupação (Fürsorge), dividem-se em formas positivas (seguir, acompanhar) e negativas (não ouvir, resistir, defender-se e fazer frente a) (idem, p. 163).

Em contraposição à situação ideal apresentada por Lévinas de um "cara-a-cara" simétrico (isto é, olhono-olho), Heidegger contempla outras formas de intersubjetividade que não possuem esse caráter simétrico, aproximando-se nisso de Foucault.

Para Heidegger, constitui a intersubjetividade uma estrutura ontológica essencial do Dasein. Sua fenomenologia hermenêutica do Dasein não aponta para um sujeito isolado que recupera o outro ulteriormente mediante a empatia (Einfühlung). Antes, o Dasein possui a possibilidade de encontrar outros entes de caráter do Dasein devido a sua abertura (Erschlossenhe it). O mundo do Dase in liberta entes que o Dasein encontra "no trabalho"; ou seja, o mundo compartilhado com os outros atua como estrutura intersubjetiva, que possibilita essa relação com o outro. Importante é o fato de uma experiência que não nasce de um sujeito isolado mas de um mundo compartilhado.

O ser-com é um modus do $D a-$ se in também na forma do ser sozinho (Alleinsein). O si mesmo não se constitui mediante relação com outro; a relação consigo mesmo é primária, embora esta implique ontologicamente a abertura para o outro (na forma do ser-com). Nem Heidegger nem Foucault renunciam à relação com o outro, nem apontam para um sujeito isolado, apesar da relação consigo mesmo aparecer ontologicamente no primeiro lugar. ${ }^{18}$

A dimensão intersubjetiva não tem sido suficientemente analisada por ambos os autores. Eles falam da indispensabilidade do outro, tematizada de formas diferentes. Porém, essa esfera intersubjetiva ocupa um segundo lugar quando se trata da constituição de esboços de si mesmo soberanos. Sublinhá-la parece-me uma tarefa necessária, pois Foucault possuía um interesse especial em apresentar a estilística da existência da Antiguidade, de forma transformada, como um contramodelo das estratégias atuais de individuação. 


\section{Fenomenologia do outro (Emma- nuel Lévinas)}

À primeira vista poderia parecer paradoxal comparar dois pensadores tão diferentes como Michel Foucault e Emmanuel Lévinas. ${ }^{19}$ Porém, parece-me interessante mostrar como determinados elementos da fenomenologia de Emmanuel Lévinas podem servir como complemento para a esfera da intersubjetividade do cuidado de si, não tematizada suficientemente no pensamento foucaultiano. Nas páginas seguintes, vou me concentrar sobre dois aspectos fundamentais do pensamento de Lévinas: 1 . Sua noção de subjetividade, que tem a intersubjetividade, a relação com o outro, como fundamento, apresentando-se, ao mesmo tempo, como uma tentativa de minar a moderna filosofia do sujeito. 2 . A experiência da sociabilidaide, a qual vai ser concebida como um desdobramento da experiência ética primária do "cara-a-cara" (face-a-face). Com respeito a Foucault, ambos os aspectos são interessantes, pois Lévinas situa a intersubjetividade num nível pré-subjetivo. Somente mediante o encontro do outro pode surgir a subjetividade. A concepção da ética (e da sociabilidade) de Lévinas, que nasce da relação cara-a-cara e renuncia a proposiçōes de verdades normativas generalizáveis, ${ }^{20}$ assemelha-se ao papel jogado pela ética para Foucault, surgida de uma situação concreta, renunciando à generalização e à universalização de açōes éticas.

\section{A subjetividade para Lévinas}

A filosofia de Emmanuel Lévinas poderia ser interpretada como uma tentativa de abandono da filosofia do sujeito. Lévinas opõe à subjetividade monádica (também chamada socratismo) da tradição filosófica uma subjetividade antimonádica. A primeira (monádica) vai ser caraterizada pelo fato que nela o outro vai ser apreendido unicamente como um outro eu. Ele não vai ser percebido na sua alteridade, na sua estranheza, como rosto (visage), porém como Lévinas afirma em Totalidade e infinitude: "O absolutamente outro é o outro" (1987d, p. 44). Essa afirmação não representa uma tautologia, mas exprime que o outro pode ser somente encontrado na sua alteridade absoluta, fato ignorado pela tradição filosófica. Lévinas opõe a subjetividade antimonádica a esse tipo de subjetividade, no qual o outro não vai ser recuperado como um outro eu, mas apreendido como absolutamente outro.

À ontologia corresponde essa subjetividade monádica (socrática) que devolve o outro para o si mesmo. A ética como experiência filosófica originária permite "aparecer a estranheza do outro". A filosofia não começa com 
a ontologia (Lévinas vai criticar o primado da ontologia em Heidegger, caraterizando-a de egologia), mas com a ética, que acontece como metafísica (idem, p. 51). A relação ética surgida do encontro do outro na sua alteridade absoluta destroça a soberania do eu. Ela vai atuar como um projeto $d e$ subjetivante. $O$ encontro do outro põe o egoísmo do eu em questão e engana a intencionalidade do sujeito (Lévinas, 1972, p. 49): "A dialética solipsista da consciência vai ser interrompida. De fato, a relação ética (...) não constitui uma variante da consciência, cujo raio parte do eu. A relação ética põe o eu em questão. Este questionamento parte do outro" (1987d, p. 280).

Na relação com o outro podem ser distinguidos três elementos recorrentes na obra de Lévinas: exterioridade, proximidade e responsabilidade.

Exterioridade: "O ser é exterioridade" (idem, p. 418). Essa fórmula não pretende destruir a subjetividade - o objetivo do livro (Totalidade $e$ infinitude) consiste na defesa da subjetividade. A exterioridade é um sinônimo da alteridade: refere-se à origem alterocêntrica da subjetividade humana: "O sujeito recebe a identidade de fora, sua unicidade procede da sua designação mediante o outro - de forma que a exterioridade ou a alteridade devem ser compreendidas como constitutivas para sua subjetividade." ${ }^{21}$
Por isso, a subjetividade nāo pode ser pensada como monádica, como autoconsciência. A exterioridade exprime a experiência do outro-nomesmo (l'autre-dans-le-même) ou a abertura do si mesmo para o outro. Ela é a condição de possibilidade do acolhimento do outro como rosto (visage), isto é, na sua absoluta estranheza. A exterioridade carateriza uma estrutura que encontra sua realização "na curvatura do espaço intersubjetivo" (1987d, p. 420), o que possibilita o encontro do outro como outro, distinguindo-se este da percepção dos objetos:

A "curvatura do espaço" exprime a relação entre entes humanos. Como o outro encontra-se por cima de mim seria simplesmente um erro, se o acolhimento que lhe preparo consistisse em "perceber" uma natureza. Por isso, a sociologia, a psicologia e a fisiologia são surdas para a exterioridade. $O$ homem, enquanto que outro, vem de fora até nós - como separado ou santo -, como rosto. Sua exterioridade, ou seja, seu apelo a mim, é sua verdade. (idem, p. 420s.)

O outro chama, me apela.

Proximidade (proximité) e responsabilidade (responsabilité) são dois conceitos inter-relacionados. A proximidade exprime a relação do umpelo-outro (l'un-pour-l'autre), uma relação de originalidade total: "O próximo me atinge antes de qualquer assunção (assomption), antes de qualquer obrigaçāo. Estou unido a ele. Relações de parentesco fora de toda biologia, contra toda lógica" (1987b, p. 
378). Ela atua como uma confusão do eu, como sua nudez (idem, p. 385).

Lévinas não compreende a proximidade num senso metafísico, mas como a responsabilidade pelo outro. $^{22}$ Ela é uma proximidade não temporal que possui um caráter de responsabilidade: "Eu tentei passar da proximidade temporal à idéia da responsabilidade para o outro que é uma 'intriga' muito mais complexa que o fato de dizer 'tu' ou de pronunciar um nome" (Lévinas, 1982b, p. 129; Cf. $1982 a$, p. 186-7). Essa responsabilidade, de origem remota, tem a substituição (substitution) como senso último: "O senso último da responsabilidade consiste em pensar o eu (moi) na passividade absoluta do si (soi) - como o fato de se colocar no lugar do outro (se substituer à l'autre), de ser seu refém (otage)" (1976, p. 411-12; cf. 1982b, p. 130). Os conceitos fundamentais nessa fenomenologia da intersubjetividade são: responsabilidade, substituição, refém.

A substituição constitui a última instância da responsabilidade; ela exprime a subjetividade do sujeito como a interrupção da identidade filosófica, da unicidade do eu. Mediante a responsabilidade pelo outro, culminando na substituição, o sujeito torna-se refém (otage), permitindo ao eu sair de si mesmo, hipostasiar-se através do acolhimento do outro. Lévinas denomina esse eu - transformado mediante o pronome pessoal oblíquo "mim" - um eu que não é mais eu, mas "mim" - como acusado: "A unicidade do eu é o fato simples de assumir a culpa (faute) do outro." ${ }^{23}$

A subjetividade nasce para Lévinas na dimensão intersubjetiva do encontro do outro. Unicamente através do acolhimento do outro na forma da substituição, do "um-pelo-outro" (l'un-pour-l'autre), pode surgir a subjetividade. Como conseqüência disso, Lévinas fala da subjetividade como hospitalidade e do sujeito como anfitriāo (1987d, p. 28, 370, 434). O conceito de hospitalidade tem um significado especial, pois exprime o apelo do outro para mim. Ele faz força sobre mim como necessitado e me converte em seu anfitrião.

\section{A experiência da sociabilidade}

A ética e a sociabilidade têm sua origem no desdobramento da relação primária do cara-a-cara. Para Lévinas, a comunidade deve se constituir sobre a base das relaçōes intersubjetivas, mediante a responsabilidade pelo outro e a substituição (idem, p. 418). Ao liberalismo opõe o pluralismo. O primeiro somente apreende o outro como um segundo exemplar do eu, enquanto que o pluralismo permite perceber o outro em sua alteridade. Sob o fundamento da proximidade do outro vai ser possível o surgimento da 
comunidade. Nesse sentido Lévinas vai falar de uma "espiritualidade da sociabilidade" entendida como uma possibilidade de se aproximar do outro (1987a, p. 152). A empatia husserliana, a qual carateriza para Lévinas um se expor ao outro (se emprunter à autrui), um assumir seu sofrimento, é empregada como metáfora do social.

O ético é colocado nesse nível primário da relação com o outro; subjetividade e sociabilidade têm um caráter ético. A ética não vai se exprimir nos princípios universais, ela não possui uma forma normativa, mas surge da situação elementar do encontro.

O pensamento de Lévinas oferece a oportunidade de dotar a dimensão intersubjetiva de uma originalidade e uma afetividade que faltam no pensamento de Foucault e Heidegger. Por uma parte, apresenta a primazia da relaçāo com o outro para o estabelecimento da relação consigo mesmo, um caminho de saída da filosofia do sujeito (passo que realiza Foucault mediante a historiografia da subjetividade); por outra parte, atua como uma possibilidade de situar a intersubjetividade no centro da constituição do sujeito. A imprescindibilidade do outro para a produção do próprio si mesmo constitui o núcleo da filosofia de Emmanuel Lévinas. Além disso, a relação intersubjetiva tem um caráter simétrico, formado sobre a situação da cara-a-cara, ou seja, uma situação olho-no-olho, experienciada como proximidade.

Para Heidegger constituía-se o ser-com (Mitsein) na dimensão intersubjetiva da fala, no ouvir-um-ao-outro (Aufeinander-hören). Esse "ouvirum-ao-outro" mostrava diferentes modi. O modelo retórico heideggeriano do "ouvir-falar" corresponde à situação assimétrica da orelha-boca; a essa situação (assimétrica) opõe-se o modelo de Lévinas, antes ético e não necessariamente transmitido lingüisticamente. $O$ modelo de Lévinas, na forma do cara-a-cara, corresponde a uma situação simétrica do olho-noolho. O ser olhado pelo outro atua como uma chamada, um apelo irresistível, pois me obriga e exige de mim uma resposta; daí as duas expressōes, uma mais forte (refém) que a outra (hospitalidade). $\mathrm{O}$ mero fato de ser olhado introduz o indivíduo numa relação ético-social. Assim, afirma Lévinas que a sociabilidade surge da relaçāo originária do cara-a-cara. Para Heidegger, pelo contrário, existem mais possibilidades que a situação ideal do olho-no-olho de Lévinas. Pode-se não ouvir a chamada ou resistir a ela.

Tentei mostrar nessas páginas como nos últimos trabalhos de Foucault a dimensão intersubjetiva está sempre presente, embora não seja suficientemente desenvolvida. Cuidado de si não é simultaneamente cuidado dos 
outros. Antes, a presença do outro é necessária para constituir a relação consigo mesmo expressa no cuidado de si. A apresentação da problemática da intersubjetividade em Heidegger permite realçar o ser-com (Mitsein) como um modus imprescindível do
Dasein. Em contraposição, a fenomenologia de Emmanuel Lévinas dota a dimensão intersubjetiva de um significado especial, não presente nem em Heidegger nem em Foucault.

\section{Notas}

${ }^{1}$ Cf., entre outros, McNay (1992, p. 165): “Foucault não pode produzir uma resposta satisfatória aos dilemas que ele mesmo se apresenta porque sua teoria do si mesmo (self) prioriza uma individualidade isolada, antes de demonstrar como a construção do si mesmo está intimamente unida a vários processos de interaçăo social." Idem, p. 174-5: "A insistência de Foucault que a preocupação com os outros é derivada do cuidado de si indica até que ponto se encontra preso aos termos da filosofia do sujeito." Cf. Heiter (1988, p. 52ss.).

${ }^{2}$ Um movimento que possibilita o encontro do outro e que tem como alvo o retorno (transformado) para si, como Foucault com precisão formula: "Pretendia se afastar e encontra-se na vertical de si mesmo" (1984a, p.19).

${ }^{3}$ Isso pode-se mostrar especialmente a partir de dois exemplos: o Alcebiades e o Banquete. 0 Alcebiades joga um papel ambivalente na concepção total da História da sexualidade (pois na versão definitiva, a análise desse diálogo ocupa um lugar muito menor que por exemplo nos cursos de 1981/1982 no Collège de France). A autenticidade desse diálogo é discutida (cf. Heiter, idem, p. 52). Na sua investigação acerca do descobrimento do a priori da intersubjetividade no platonismo, Christoph Jermann não presta atenção a esse diálogo (cf. Jermann, 1986). O Alcebíades vai ser escolhido por Foucault para mostrar a relação com o outro, necessária na estrutura do cuidado de si. No Banquete, o outro é elevado a um status de sujeito mediante o movimento do eros/epimeleia. Isso exclui a percepção do outro como objeto, contida na concepção monádica da subjetividade. Trata-se antes de uma relação intersubjetiva simétrica e recíproca, consistente em dois sujeitos, na qual cada um atua para o outro como intermediário em sua autoconstituição. Esse testemunho, importante para a dimensão intersubjetiva do cuidado de si, perde importância, porém, quando Foucault o desqualifica como precursor da formação de uma hermenéutica do desejo. A nãotematização no Uso dos prazeres da autoconstituição epicurista, centrada no sujeito, ou seja, individualista, a favor da autoconstituiçăo socrática comunitária, beneficia a dimensão intersubjetiva (embora agonística) nas suas análises do cuidado de si grego. Sobre a difererença entre autoconstituiçăo epicurista e socrática, cf. Wolfstetter (1988, p. 83ss.).

- Idem, p. 136. Uma formulação similar em Foucault (1984c, p. 19): "Então gostaria de mostrar como se introduz o governo de si mesmo em uma prática do governo dos outros." 
${ }^{5}$ Foucault 1985b, p. 40; 1985a, p. 14ss. Por conseguinte não tem sentido afirmar, como faz Lois McNay (1992, p. 165s., 174s., 180): Foucault permanece preso à filosofia do sujeito ou prefere uma constituição do sujeito isolada. Ele nāo faz isso, nem nas suas análises históricas sobre a autoconstituição greco-romana nem nos esforços de atualização dessa estilística da existência (lá, trata-se de subjetivações coletivas como formas de vida).

6 Jermann mostra como o cárater de fim em si mesmo do diálogo é também constitutivo da filosofia platônica, na medida em que ele (o diálogo) foi apreendido como forma de resistência frente as conseqüências políticas da retórica sofista (p. 75). Toda a primeira parte do livro de Jermann, $O$ descobrimento do a priori da intersubjetividade (Die Entdeckung des Aprioris der Intersubjetivität), é muito ilustrativa. Jermann não se refere, porém, ao Alcebíades, onde resulta muito explícita a esfera intersubjetiva exprimida na forma dialógica.

7 A continuação refiro-me ao artigo de Bern Heiter (1988), o qual analisa a relação entre o cuidado de si e a esfera intersubjetiva partindo do Alcebíades. Não obstante, suas conclusōes diferem das minhas, pois para Heiter Foucault permanece preso na subjetividade monádica. Cf. Wolfstetter (1988) que alude também à constituição intersubjetiva do sujeito na filosofia socrático-platônica, embora não se ocupe explicitamente do Alcebíades.

${ }^{8}$ Se aceitarmos a diferenciaçăo intersubjetividade basal versus intersubjetividade prática de Bern Heiter (1988, p. 55ss.) - onde a primeira baseia-se na redução teleologica de açōes orientadas ao entendimento, isto é, intersubjetividade como fim para outra coisa, por exemplo: o cuidado de si; enquanto a segunda vai ser contemplada como um fim em si mesmo, por exemplo: amor, amizade - trata-se nesse caso de uma forma de intersubjetividade basal, a qual pode ser apreendida como condição prévia e contexto transcendental da relação consigo mesmo. A dimensão da intersubjetividade basal não é suficientemente acentuada por Foucault, embora ele não negue a base intersubjetiva de seu aparelho categorial: "O sujeito forma-se em práticas reais e analisáveis historicamente" (1987, p. 289). Precisamente as tecnologias do si mesmo e os jogos da verdade (os quais lembram os jogos da linguagem wittgensteinianos) exigem essa esfera intersubjetiva (basal). Se para Foucault o problema consiste em "dar-se as regras juridicas, as técnicas de conduta e tambem a moral, o ethos, a praxis do si mesmo que permitam jogar dentro dos jogos do poder com a mínima quantidade de dominio" (1985a, p. 25), então essas regras, essas técnicas de conduta, que permitem produzir a auto-relaçāo desejada, serão unicamente compreensíveis numa dimensão intersubjetiva (basal). A não- tematização da intersubjetividade basal não impede Foucault de prestar atenção nas formas de intersubjetividade pratica (amizade), sempre sob a perspectiva de uma atualizaçáo da estilística da existéncia. Cf. meu artigo: Foucaults letztes, unvollendetes Projekt: Eine Rehabilitierung der Freundschaft.

- H.D. Voigtlaender, citado por Jermann (1986, p. 68s.). Como Werner Jaeger realça (idem), năo se trata do caso socrático da irrelevåncia da separaçáo modema entre ética e política, mas da superaçăo dessa separação. Jermann renuncia a diferenciação comum, segundo a qual S6crates é apresentado como pensador ético e Platão como pensador político, precisamente pelo significado que tem para ambos os autores a dimensão intersubjetiva (basal) do filosofar dialógico, como "conditio sine qua non da saúde, ou então do restabelecimento da vida política" (idem). Cf. Arendt (1993, p. 389). 
10 Foucault (1985a, p. 21). Essa relação será muito ilustrativa na análise da amizade como forma de intersubjetividade prática - sobretudo no caso de Aristóteles - a qual vai ser apreendida como conjunção entre ética e política (Voelke, 1961, p. 61), como vínculo da comunidade, pois ela possibilita o igualamento político, condição do surgimento da comunidade (Arendt, 1993, p. 387).

${ }^{11}$ Idem, 62-63. Cf. Forst (1990, p. 177-8). O gozo do timé, da estima pública como valor supremo na Grécia clássica, é unicamente compreensível na forma de intersubjetividade (basal). Cf. Jermann (1986, p. 73); Schmid (1991, p. 350): "Nos olhos do outro aparecia a estética da existência própria e era somente assim apreensível, quando o outro reflexava-a."

Essa técnica terá um grande alcance nos séculos I e II de nossa era.

${ }^{13}$ Foucault (1985b, p. 38). Em seus últimos cursos sobre a parrhesia, Foucault (1988, p. 17) sublinha o papel do mestre como possuidor da parrhesia: "Esta virtude, obrigaçāo e técnica devem sobretudo caraterizar àqueles que têm a tarefa de dirigir os outros e especialmente àqueles que devem guiar os outros em seus esforços, suas tentativas de se constituir em sua relação consigo mesmo." Cf. Flynn (1987, p. 218).

${ }^{14}$ Foucault (1985b, p. 43): "Existe uma forte tendência a praticar, divulgar e desenvolver a práxis do si mesmo fora da instituiçāo filosófica e até da profissão filosófica, e a fazer dela um modus de relaçăo determinado entre os indivíduos, transformando-a em um tipo de princípio, de controle do indivíduo pelos outros, uma forma de construção, desenvolvimento, constituição de uma relação consigo mesmo que encontra seu ponto de apoio e seu meio num outro indivíduo que não é necessariamente um filósofo, embora sejam indispensáveis para ele uma passagem pela filosofia e a existência de conceitos filosóficos."

15 Esse fato levou alguns comentadores a duvidar da autenticidade da correspondência (ou seja, se esta verdadeiramente teve lugar) (Knoche, 1975, p. 152). Independentemente disso, existe nessas cartas uma reivindicação de universalidade importante. Lucilius é o destinatário direto; na correspondência Sêneca mostra-se como o diretor de sua alma, porém ele não é o único a cuja alma Sêneca dirige-se. A correspondência transporta uma auto-estilização com fins didáticos, a qual antecipa as confissōes de Agostinho: "Para convencer seus leitores de que a educaçāo moral tem o efeito desejado, diz de si mesmo que se encontra numa transformaçāo interna" (Misch, 1950, p. 429). Se o outro como destinatário é um outro concreto e existente ou não, a auto-estilização exige pelo menos a presença de um outro (virtual). K.H. Bohrer (1987, p. 214ss.) tem analisado essa funçăo de autoencenação nas correspondências românticas: "Estas cartas não (procuravam) realmente um diálogo, uma verdadeira correspondência (...), mas apresentavam respectivamente encenaçōes narcisistas (...). O caráter dialógico, determinante das cartas do século XVIII (...), perdeu-se em benefício de construtos monológicos de um eu que propriamente não permite nenhuma resposta mais, senāo sempre novas entradas da autoapresentação para o papel da construção do eu." O papel do destinatário é o do "refletor" da "identidade lingüístico-metafórica respectivamente adotada" (idem, p. 238). 
16

Cf. Dreyfus (1992, p. 148). Frente a Husserl, "Heidegger (...) começa com nossa forma social normal de ser, que ele denomina ser-com. Ele não negaria que em casos de desmoronamento nós podemos formar crenças sobre as crenças dos outros, etc. (...) . Na maior parte do tempo, porém, Heidegger afirma que nós trabalhamos com outros sem ter nenhuma crença sobre eles ou crenças em geral."

17 Idem, p. 121. Semelhantemente à p. 123: "A abertura do co-Dasein dos outros, pertencente ao ser-com, significa: na compreensão do ser do Dasein já subsiste uma compreensão dos outros porque seu ser é ser-com."

18 Mas, como afirma Georg Friedmann (Hadot, 1991), não se deve "para preparar a revoluçāo" primeiro "fazer-nos dignos dela?" Não precede uma revolução da alma toda revolução mundial?

19 Que Heidegger exerceu grande influência sobre seu pensamento, tem sido sublinhado freqüentemente por Foucault. Porém, Lévinas nunca foi mencionado.

${ }^{20}$ Lévinas (1985, p. 106): "A lei é o resultado do fato de encontrar o outro."

${ }^{21}$ Rolland (1991, p. 148). Cf. Levinas (1987d, p. 419); Treziak (1975, p. 75ss).

${ }^{22} \mathrm{Em}$ alguns lugares parece que Lévinas separa proximidade e responsabilidade, enquanto que em outros estabelece uma relaçăo de identidade: proximidade = responsabilidade, ou a proximidade como condição de possibilidade da responsabilidade. Eu sinto uma responsabilidade pelo outro precisamente por se encontrar próximo - em uma proximidade mais originária que a proximidade espacial.

${ }^{23}$ Lévinas (1974, p. 143, 16-7, 33, 126, 134, 142, 145, 150, 163). Cf. 1982a, p. 187; 1972, p. 98; Funk, 1989 , p. 347, 376-7, 381, 403-4. Lévinas também caracteriza a dessubjetivação exprimida na passagem do "eu" ao "mim" como passagem do "Eu" (Moi com maiúscula) ao "eu" (moi com minúscula). Cf. 1972, p. 99: "Da responsabilidade suplementar vem que a subjetividade não é o Eu (Moi), mas o eu (moi)." Cf. 1974, p. 16ss.

\section{Referências Bibliográficas}

ARENDT, H. Philosophie und Politik. In: Deutsche Zeitschrift für Philosophie 2. 1993.

BOHRER, K.H. Der romantische Brief. In: BOHRER, K.H. Die Entstehung ästhet ischer Subjektivität. München, 1987.

DREYFUS, H.L. Being-in-the-world. Cambridge, Mass. 
DREYFUS, H.,RABINOW, P.1990 Was ist Mündigkeit. In:, ERDMAN, E., FORST, R., HONNETH, A. (orgs.) Ethos der Moderne. Foucaults Kritik der Aufklärung. Frankfurt/Main, 1992.

FLYNN, T. Foucault as Parrhesiast, Philosophy and social criticism 12.

FORST, R. 1990 Endlichkeit, Freiheit, Individualität. IN: ERDMAN, E., FORST,

R., HONNETH, A. Orgs. Ethos der Moderne. Foucaults Kritik der Aufklärung. Frankfurt/Main, 1987.

FOUCAULT, M. (1984a) L Usage des plaisirs. Paris. Trad. alemã: Der Gebrauch der Lüste. Frankfurt/Main, 1989.

. (1984b) Le souci de soi. Paris. Trad. alemã: Die Sorge um sich. Frankfurt/Main, 1989.

. (1984c) Le souci de la vérité. Magazine littéraire 207, 1984.

. (1985a) Freiheit und Selbstsorge, Freiheit und Selbstsorge. Frankfurt/Main, 1985.

. (1985b)Hermeneutik des Subjekts, Freiheit und Selbstsorge. Frankfurt/Main, 1985.

. (1987) Zur Genealogie der Ethik. In: DREYFUS, H.; RABINOW, P. Jenseits von Strukturalismus und Hermeneutik. Frankfurt/Main, 1987.

. Das Wahrsprechen des Anderen. In: REUTER, U., WOLFSTETTER, L., KOCYBA, H. (orgs.) Das Wahrsprechen des Anderen. Frankfurt/Main, 1988. . Résumé des cours (1970-1982). Paris, 1989.

FUNK, R. Sprache und Transzendenz im Denken von Emmanuel Lévinas. Zur Frage nach einer neuen philosophischen Rede von Gott. Freiburg, München, 1989.

GUERRERO ORTEGA, F. Foucaults letztes, unvollendetes Projekt: Eine

Rehabilitierung der Freundschaft. In: . Das Argument. Zeitschrift fuer

Philosophie und Sozialwissenschaften.

HADOT, P. Philosophie als Lebensform. Berlin, 1995.

HEIDEGGER, M. Sein und Zeit. Tübingen, 1986.

HEITER, B. Intersubjektivität und die "Sorge um sich". Kommentierende Bemerkungen zu Foucaults interpretativer Analytik der antiken Ethik. In: REUTER, U.; WOLFSTETTER,L.; KOCYBA, H. (orgs.) Das Wahrsprechen des Anderen. Frankfurt/Main, 1988.

HUIZING, K. Das Sein und der Andere. Lévinas' Auseinandersetzung mit Heidegger. Frankfurt/Main, 1988.

JERMANN, C. Philosophie und Politik. Untersuchungen zur Struktur und Problematik des platonischen İdealismus. Stuttgart-Bad Cannstatt. 
KNOCHE, U. 1975 Der Gedanke der Freundschaft in Senecas Briefen and Lucilius. MAURACH, G. Org. Seneca als Philosoph. Darmstadt, 1986.

LÉVINAS, E. Humanisme de l'autre homme. Montpellier, 1972.

. (1974) Autrement qu'être ou au-delà de l'essence. La Haye, 1974.

- (1976) Difficile liberté. Paris, 1976.

. (1982a) La pensée de l'être et la question de l'autre, De Dieu qui vient à

l'idée. Paris, 1982.

- (1982b) Questions et réponses, de Dieu qui vient à l'idée. Paris, 1982.

. (1985) Gespräch mit Lévinas, Engelmann, P. (org.) Philosophien. Wien,

1985.

- (1987a) De la intersubjectivité. Notes sur Merleau-Ponty, Hors Sujet.

Montpellier, 1987.

. (1987b) De la sensibilité, hors sujet. Montpellier, 1987.

- (1987c) Entretiens Emmanuel Lévinas, Francois Poirié. In: POIRIÉ, F.

Emmanuel Lévinas, Qui êtes-vous? Lyon, 1987.

. (1987c) Totalität und Unendlichkeit. München, 1987.

MCNAY, L. Foucault and Feminism. Cornwall, 1992.

MISCH, G. Geschichte der Autobiographie I,2. Bern, 1950.

PLATÃO Alkibiades I, Sämtliche Werke. Band I. Koeln, 1969.

ROLLAND, J. Postface, Lévinas, E.: La mort et le temps. Paris, 1991.

SCHMID, W. Auf der Suche nach einer neuen Lebenskunst. Frankfurt/Main, 1991.

SCHOTTLAENDER, R. Epikureisches bei Seneca. Ein Ring um den Sinn von

Freude und Freundschaft. In: MAURACH, G (org.). Seneca als Philosoph.

Darmstadt, 1975.

SORENSEN, V. Seneca. The Humanist at the Court of Nero. Bath, 1984.

TAURECK, B. Lévinas zur Einführung. Hamburg, 1991.

TREZIAK, H. Die konkrete Intentionalität der Exteriorität. Untersuchungen zur Apriori Struktur der Intersubjektivität nach E. Lévinas, Inaug. Diss. München, 1975.

WOLFFSTETTER, L. Foucaultiade II. REUTER, U., WOLFSTETTER, L., KOCYBA, H. (orgs.) Das Wahrsprechen des Anderen, Frankfurt/Main, 1988. 